\title{
Expression of p63, p53 and Ki-67 in Patients with Cervical Intraepithelial Neoplasia
}

\author{
Androniks MITILDZANS' ${ }^{1}$ Anastasija ARECHVO², Dace REZEBERGA ${ }^{3}$, Sergejs ISAJEVS ${ }^{4}$ \\ 'Department of Oncology, Riga East University Hospital, RIGA, LATVIA, ${ }^{2}$ University of Vilnius, Faculty of Medicine, VILNIUS, LITHUANIA, ${ }^{3}$ Department of \\ Gynecology and Obstetrics, Riga Stradins University, RIGA, LATVIA, ${ }^{4}$ Department of Pathology, University of Latvia, Faculty of Medicine, RIGA, LATVIA
}

\begin{abstract}
Objective: Cervical intraepithelial neoplasia (CIN) is a dysplastic process in cervical squamous epithelium and carries a risk of progression to cervical cancer. The aim of this study was to compare expression of three biomarkers named p53, p63 and Ki-67 in patients with various grades of cervical intraepithelial neoplasia and in a control group.
\end{abstract}

Material and Method: 58 patients were enrolled in the study. Each patient underwent a colposcopy-guided biopsy of the cervix. Immunostaining for markers (p53, p63 and Ki-67) was performed on tissue samples of normal cases ( $\mathrm{n}=10)$, CIN I ( $\mathrm{n}=20)$, CIN II ( $\mathrm{n}=14)$, and CIN III ( $\mathrm{n}=14)$.

Results: Our study showed a significant increase of the expression of the analyzed biomarkers in most patients with CIN III compared to CIN II and CIN I. Furthermore, p53 and p63 were significantly increased in CIN I compared to the control group.

Conclusion: The expression of Ki-67, p63 and p53 differed between CIN I, CIN II and CIN III. p63 and p53 were reliable biomarkers to distinguish reactive changes from CIN I, while all three biomarkers (Ki-67, p53 and p63) had a high degree of sensitivity and specificity to distinguish between CIN III, CIN II and CIN I.

Key Words: Cervical intraepithelial neoplasia, p63, p53, Ki-67

\section{INTRODUCTION}

Each year, 330.000 new Cervical Intraepithelial Neoplasia (CIN) cases occur in the European Union, with about a half of them diagnosed as CIN I (1). CIN is usually a long preinvasive process, characterized microscopically as a range of events progressing from cellular atypia to various grades of dysplasia, which over time can progress to invasive cervical carcinoma (2).

The new WHO classification applied LSIL (Low-grade Squamous Intraepithelial Lesion) and HSIL (Highgrade Squamous Intraepithelial Lesion) terminology (2). However, previous classifications classified CIN as CIN I, CIN II and CIN III based on the degree of dysplasia (3). Accurate histological grading of CIN lesions was important for clinical management of patients, because CIN lesions were monitored and treated differently. For example, CIN I was usually regarded as benign and no therapy was indicated, because it regresses in about $80 \%$ of cases (4). CIN II and CIN III were regarded as precursors of invasive carcinomas and therapy (conization or other less invasive procedures) was indicated, as $0.2-4.0 \%$ of CIN II and CIN III cases can progress to cervical carcinoma within 12 months (4-7). There were no specific clinical symptoms

(Turk Patoloji Derg 2017, 33:9-16)

Received : 20.07.2015 Accepted : 02.10.2016 indicating the presence of CIN (2). In practice, screening was usually made by cytological Pap smear testing, which successfully helped to reduce the incidence of cervical cancer $(2,8)$.

Histological assessment of cervical biopsies that was often considered as the "gold standard" can be significantly hampered by intra- and interobserver variability (2-4). Accurate diagnosis and prediction of progression risk were important issues in the clinical management of patients with CIN (1, 6-8). Therefore, identification of specific biomarkers for CIN diagnosis is of particular importance.

The p53 is a tumour suppressor gene, which specifically inhibits cell cycle progression and promotes DNA repair and/or apoptosis. p53 inactivation has been correlated with a critical step in the development of various human cancers (9). Inactivation may result from a number of events, including mutation of the p53 gene and binding of the p53 gene to cellular or viral proteins, such as the HPV E6 oncoprotein (9-10). High-risk human papillomaviruses are closely associated with cervical cancer and its precursor lesions via interactions between the E6 and E7 oncoproteins and cell-cycle regulatory proteins, such as $\mathrm{p} 53$ and $\mathrm{pRb}$, respectively (11-14).

Correspondence: Sergejs ISAJEVS

University of Latvia, Faculty of Medicine,

Department of Pathology, RIGA, LATVIA

E-mail: sergisajevs@inbox.lv Phone: +37 167536482 
p63, a homologue of the tumour suppressor gene p53 is expressed in embryonic, adult murine and human basal squamous epithelium and encodes both transactivating and dominant negative transcript isoforms. p63 expression by immunostaining delineated basal and parabasal cells of maturing ectocervical squamous mucosa, squamous metaplasia in the cervix, and basal and subcolumnar cells of the cervical transformation zone (12).

The expression of several host genes is effected by the oncogene products of HPV, including those involved in cellular proliferation, such as Ki-67 (13).

Previous studies have focused on various CIN biomarkers; however, there have been only a few studies comparing the expression of different biomarkers and the appropriate panel of biomarkers for accurate CIN diagnosis. Previous studies found that $\mathrm{Ki}-67$ and p63 expression differed between CIN I and CIN III $(6,9)$. The aim of our study was to evaluate the expression of biomarkers p53, p63 and Ki-67 for accurate CIN diagnosis and grading.

\section{MATERIALS and METHODS}

Fifty-eight patients aged 18-46 years and referred to the Department of Gynecology at Riga East University Hospital were enrolled in the study. The study conformed to the Declaration of Helsinki. The study protocol was approved by the Committee of Ethics, Institute of Experimental and Clinical Medicine, University of Latvia (Riga, Latvia). All patients signed informed consent prior to enrolment.

Exclusion criteria were previous treatment for cervical disease (including loop electrosurgical excision procedure (LEEP)), cold-knife conization, cryotherapy, LASER therapy, or hysterectomy, prior chemotherapy or radiation treatment for cervical neoplasia, pregnancy, HIV infection, and inability to give informed consent. The study consisted of 58 women, including 20 cases of CIN I, 14 cases of CIN II, 14 cases of CIN III and 10 cases of the control group without CIN. All patients underwent a colposcopy-guided cervical biopsy.

Tissue Processing, Histology, Immunohistochemistry: Formalin-fixed paraffin embedded tissue was cut in $4 \mu \mathrm{m}$ thick sections. The sections were stained with H\&E for histopathologic examination. For immunohistochemistry, antigen retrieval was achieved by treatment in a domestic microwave for 30 minutes in EDTA buffer $\mathrm{pH}=9.0$. Sections were incubated in $3.0 \% \mathrm{H}_{2} \mathrm{O}_{2} / \mathrm{PBS}$ to quench endogenous peroxidase activity, and then blocked with protein block (Dako). The slides were then incubated 1 hour at room temperature with primary antibodies against the following antigens: p53 (rabbit monoclonal DAKO, Denmark, and dilution 1:50, clone 318-6-1), p63 (mouse monoclonal, DAKO, Denmark, M7317, dilution 1:50, clone DAK-p63) and mouse monoclonal Ki-67 (DAKO, Denmark, dilution 1:150, M7240, clone MIB-1). The EnVision kit was used for visualization of bonding of primary antibodies. 3'3-diaminobenzidine-tetrahydrochloride (DAB) was applied as chromogen (7 minutes) Sections were counterstained in haematoxylin (2 minutes). For positive control, tissue of human palatine tonsils (for Ki67), squamous cell lung carcinoma (for p63) and colon adenocarcinoma (for p53) tissue were used. Negative controls were performed by omitting the primary antibody.

Evaluation of p16, Ki-67 and p63 Expression: The immunoreactivity of Ki-67 and p63 was judged as positive when more than $10 \%$ of the cell nuclei showed strong intensity staining. The immunoreactivity of p53 was judged as positive when more than $1 \%$ of the cell nuclei showed strong intensity staining. To evaluate the Ki-67, p63 and p53 positive cells, at least 1000.00 dysplastic cells were counted. At least ten high-powered fields (magnification $\times 400$ ) were assessed. Only cells with nuclear staining were considered positively stained cells. The results were expressed as cells per square millimeter.

HPV Testing: All patients underwent HPV testing from cervical smears. The Aptima HPV assay is an in vitro nucleic acid amplification test for the qualitative detection of E6/E7 viral messenger RNA (mRNA) from 14 high-risk types of human papillomavirus (HPV) in cervical specimens. The high-risk HPV types detected by the assay include: 16,18 , $31,33,35,39,45,51,52,56,58,59,66$, and 68 . The Aptima HPV assay does not discriminate between the 14 high-risk types (15).

Statistical Analysis: Group data are expressed as mean \pm SD. The D'Agostino-Pearson omnibus test was used for the assessment of normality. Differences between groups (patients age) were analyzed using one-way analysis of variance (ANOVA), Chi-squared test (the numbers of positive cases) and Kruskal-Wallis test with Dunns post test for morphological data (p53, p63 and Ki-67 positive cells). A p-value of $<0.05$ was considered statistically significant. Data analysis was performed using SPSS software, version 21 (SPSS Inc., Chicago, IL, USA).

\section{RESULTS}

Table I shows the clinicopathological characteristics of patients. There were no differences in patient age between the groups. The HPV in patients with CIN was more frequently detected compared to the control group. In 
patients with CIN III, HPV was more frequently found compared to patients with CIN II and CIN I (Table I).

Figure 1A-D shows cervical tissue with CIN I, CIN II and CIN III. Our study results show increased Ki-67 expression in multilayer squamous epithelium in CIN III as compared to CIN II and CIN I patients ( $58 \pm 15$ vs. $29 \pm 12$ cells/ $\mathrm{mm}^{2}, \mathrm{p}<0.0001$ and $58 \pm 15$ vs. $10 \pm 3$ cells $/ \mathrm{mm}^{2}, \mathrm{p}<0.001$, respectively; Figure 2). In addition, patients with CIN II had increased Ki-67 expression compared to CIN I and control group $(\mathrm{p}<0.0001)$. However, there was no difference between Ki-67 expression in the control group and CIN I. Furthermore, Ki-67 expression was detected in all patients with CIN II and CIN III, whereas in patients with CIN I it was positive in $30 \%$ of cases. Figure 3A-D shows Ki-67 positive cells.

p53 expression was observed in the control group. However in patients with CIN III, it was observed in $71 \%$ of cases, and in CIN II and CIN I in 50\% and $10 \%$ of cases, respectively.

Patients with CIN III demonstrated increased p53 expression, compared to CIN II and CIN I patients $(9 \pm 4$ vs. $5 \pm 3$ cells $/ \mathrm{mm}^{2}, \mathrm{p}<0.0001$ and $9 \pm 4$ to $2 \pm 1$ cells $/ \mathrm{mm}^{2}$, $\mathrm{p}<0.0001$, respectively; Figure 4). Furthermore, there is a significant difference between p53 expression in patients with CIN I compared to CIN II and control group. Figure 5A-D demonstrated p53 positive cells.
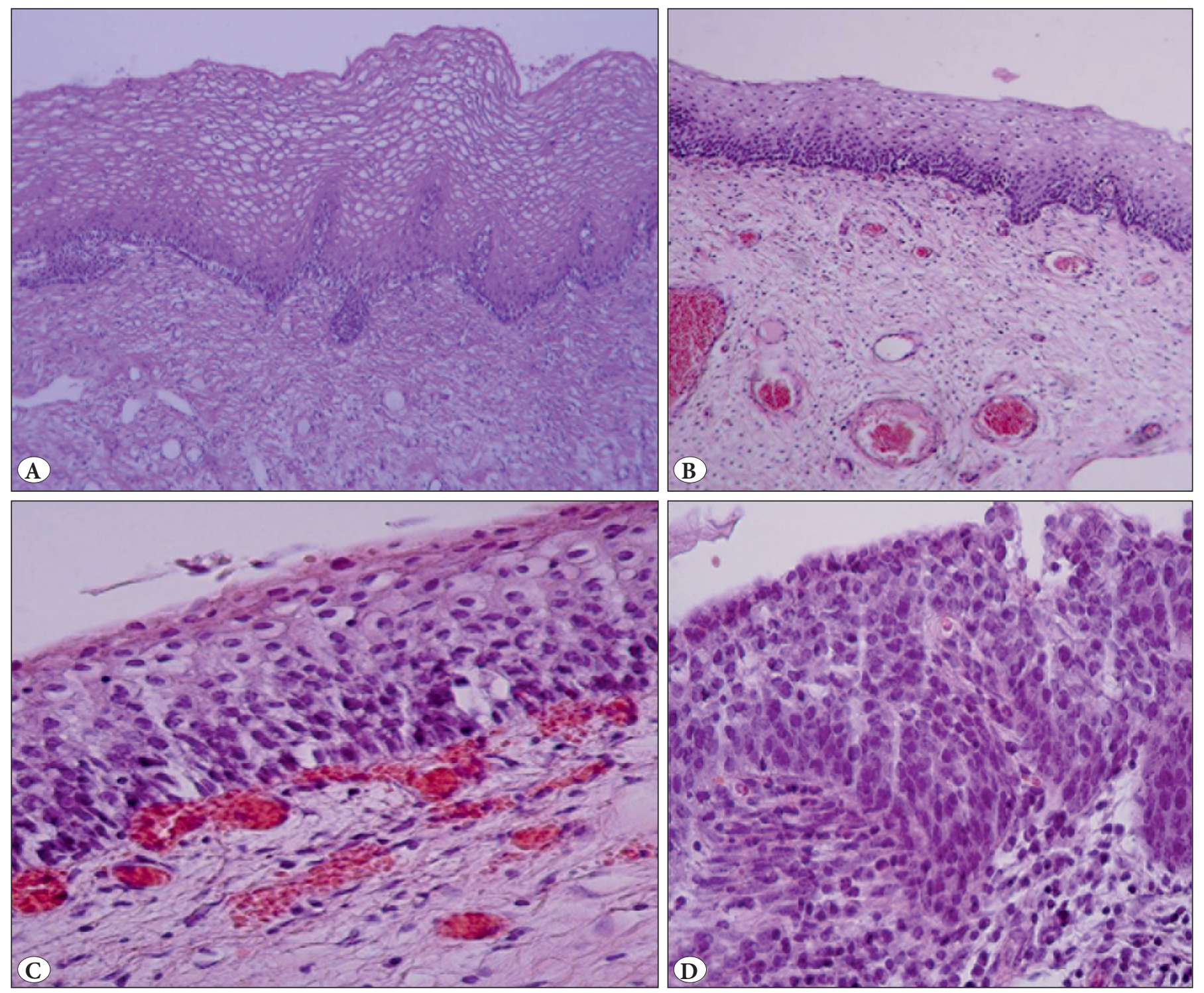

Figure 1: Representative photomicrograph of cervical tissue from A) Control group (H\&E; x100), B) CIN I (H\&E; x100), C) CIN II (H\&E; x200), D) CIN III (H\&E; x200). 
Table I: Patients' clinicopathological characteristics

\begin{tabular}{lcccc}
\hline Characteristics & Control group & CIN I & CIN II & CIN III \\
\hline Number of enrolled subjects, $n$ & 10 & 20 & 14 & 14 \\
\hline Age, years & $32 \pm 12$ & $32 \pm 14$ & $31 \pm 12$ & $21 \pm 11$ \\
\hline HPV positive cases & $2(20 \%)$ & $8(40 \%)^{*}$ & $6(42 \%)^{*}$ & $9(64 \%)^{*}$ \\
\hline K-67 positive cases & $2(20 \%)$ & $6(30 \%)^{*}$ & $14(100 \%)^{* * *}$ & $14(100 \%)^{* * * *}$ \\
\hline p53 positive cases & $0(0 \%)$ & $2(10 \%)^{*}$ & $7(50 \%)^{*}$ & $10(71 \%)^{*, * *}$ \\
\hline p63 positive cases & $2(10 \%)$ & $6(30 \%)^{*}$ & $14(100 \%)^{* * * *}$ & $14(100 \%)^{* * * *}$ \\
\hline
\end{tabular}

${ }^{\star} \mathrm{p}<0.05$ compared to the control group; ${ }^{\star *} \mathrm{p}<0.01$ compared to patients with CIN I. One-way ANOVA for patients demographical data (age) and Chi-squared test for the analysis of HPV, Ki-67, p53 and p63 positive cases.

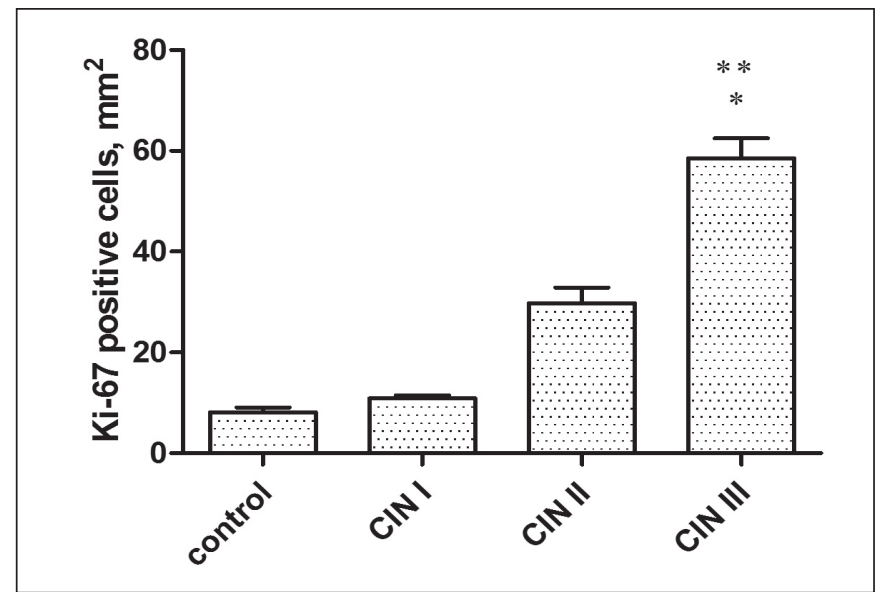

Figure 2: Ki-67 expression in patients with CIN and control group. ${ }^{*} \mathrm{p}<0.0001$ compared CIN III vs. CIN II and vs. CIN I; ${ }^{*} \mathrm{p}<0.0001$, compared control group vs. CIN III and vs. CIN II. Kruskal-Wallis test followed by Dunns' post test.

Patients with CIN III showed increased p63 expression in multilayer squamous epithelium compared to CIN II and CIN I patients $\left(67 \pm 18\right.$ vs. $40 \pm 14$ cells $/ \mathrm{mm}^{2}, \mathrm{p}=0.0002$ and $67 \pm 18$ vs. $14 \pm 4$ cells $/ \mathrm{mm}^{2}, \mathrm{p}<0.0001$, respectively; Figure 6). In addition, patients with CIN II had increased p63 expression compared to CIN I and control group $(\mathrm{p}<0.0001)$. Furthermore, p63 expression was detected in all patients with CIN II and CIN III, whereas in patients with CIN I it was positive in $30 \%$ of cases. Figure 7A-D demonstrated $\mathrm{p} 63$ positive cells.

\section{DISCUSSION}

Cervical cancer remains one of the leading causes of cancer death in women all over the world (2). In order to reduce cervical cancer incidence, cytological screening has been successful introduced in different countries $(14,16,17)$. However, there is still a high percentage of women who develop invasive cervical cancer. HPV is an important causal factor, but other etiologic and genetic factors may be involved in tumor progression $(17,18)$.
Cervical cancer is preceded by a long period of premalignant disease (17-19). During this period of progression, different genes, such as E6 and E7 and disturbance of the cell cycle mechanism cause subsequent alteration in the expression of some proteins, such as p53, p63 and Ki-67 (18-20).

Diagnosis and grading of cervical intraepithelial neoplasia (CIN) is part of routine pathology practice. However, discriminating between reactive changes and CIN I, and between CIN II and CIN III may be still challenging. Reactive epithelial changes were usually associated with inflammation, pregnancy and hormonal therapies, which can mimic CIN $(2,3)$.

Our results demonstrate that $\mathrm{Ki}-67, \mathrm{p} 63$ and p53 expression is significantly increased in CIN III compared to CIN I and CIN II. In addition, there is a significant difference between the expression of these biomarkers in CIN II and CIN III. Furthermore, the expression of p53 and p63 in CIN I is significantly increased compared to control group.

In CIN, p53 expression is observed predominantly in CIN II and CIN III $(9,12)$. It has been shown that the p53 is bound and inactivated by E6 oncoproteins in HPV-positive squamous cell carcinoma of the uterine cervix. Degradation of p53 by HPV E6 could therefore result in low expression of $\mathrm{p} 53$ in cervical lesions, but the relationship between HPV and p53 immunohistochemistry staining in cervical lesions is controversial $(9-12,21-24)$. Our study demonstrates that patients with CIN III have increased p53 expression, compared to CIN II and CIN I patients, but the association between HPV and p53 expressions is not observed.

By contrast, some studies have demonstrated no significant difference in p53 expression between CIN I, CIN II and CIN III $(18,19)$. In addition, a few studies demonstrated that dysplastic tissue did not express p53 (21). However, some studies showed that the expression of p53 increased proportionally to the grade of CIN and cervical cancer (25). 

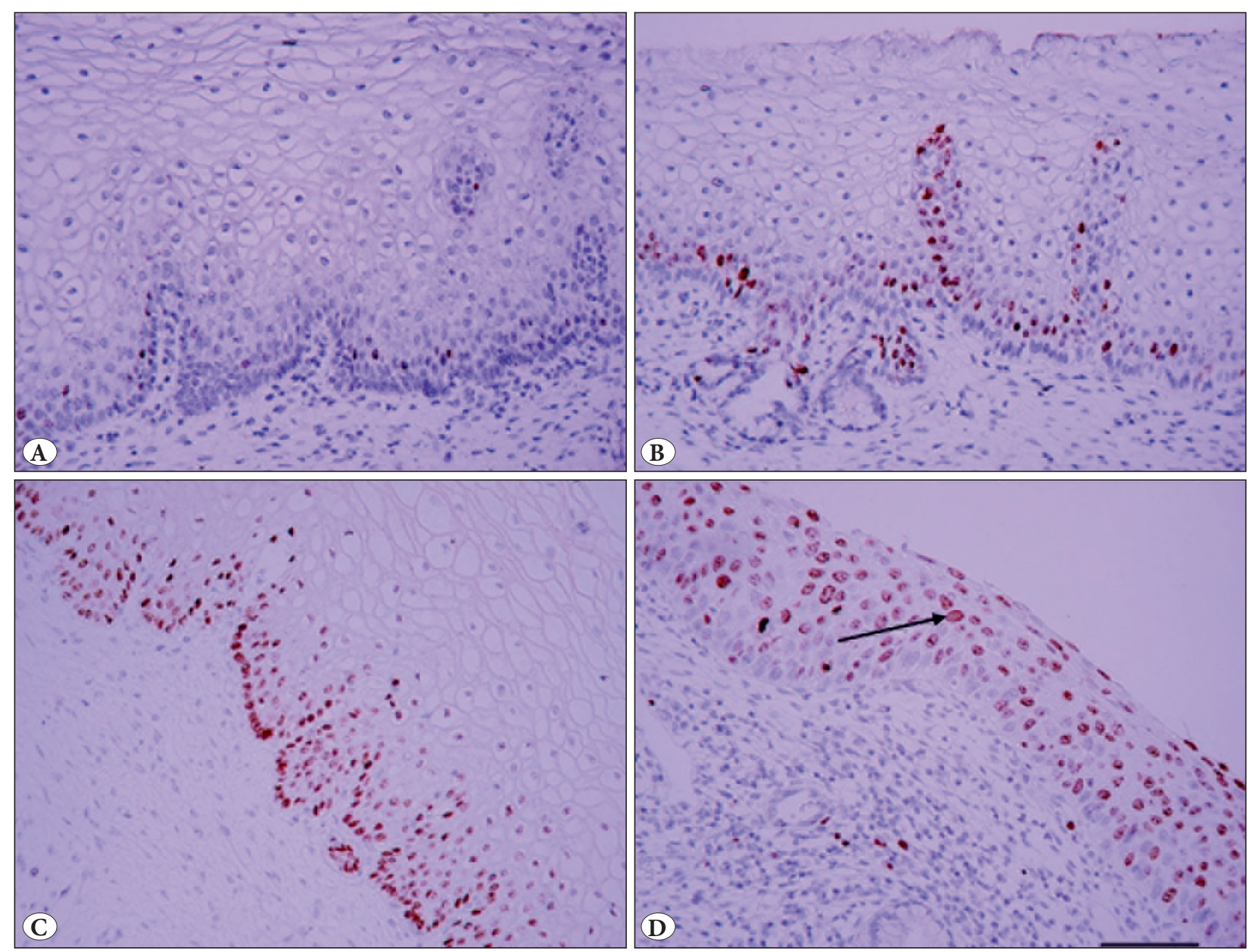

Figure 3: Representative photomicrograph of Ki-67 expression in A) Control group, B) CIN I, C) CIN II and D) CIN III. (Ki-67; x200, scale bar-100 $\mu \mathrm{m}$, arrow indicated positively stained cells).

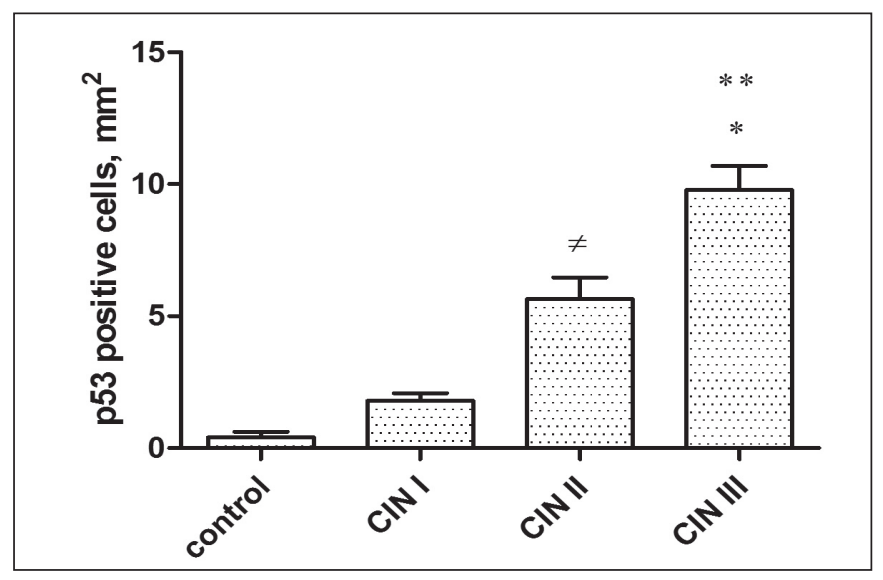

Figure 4: p53 expression in patients with $\mathrm{CIN}$ and control group. ${ }^{\star} \mathrm{p}=0.002$ compared CIN III vs. CIN II; ${ }^{* *} \mathrm{p}<0.0001$, CIN III vs. CIN I and control group; $\mathrm{p}<0.0001$ compared CIN II vs. CIN I and CIN II vs. CIN III and vs. control group; $\mathrm{p}=0.02$, compared control group vs. CIN I. Kruskal-Wallis test followed by Dunns' post test. p63 is the precursor of p53 and stained the basal cells, being a useful marker of squamous neoplasms within the cervix $(12,14)$. Our study demonstrated increased p63 expression in CIN III compared to CIN II and CIN I. Previous studies support our evidence that p63 was associated significantly with CIN III (21). However, our results extend this observation by demonstrating that $\mathrm{p} 63$ was also increased in CIN I compared to control group.

In addition, it has been shown that in early cervical neoplasia, p63 expression is inversely correlated with both squamous cell maturation and non-squamous differentiation in CIN $(25,26)$. Our results support previous findings and extend them by demonstrating the significant difference in p63 expression between control group and various degrees of CIN. 

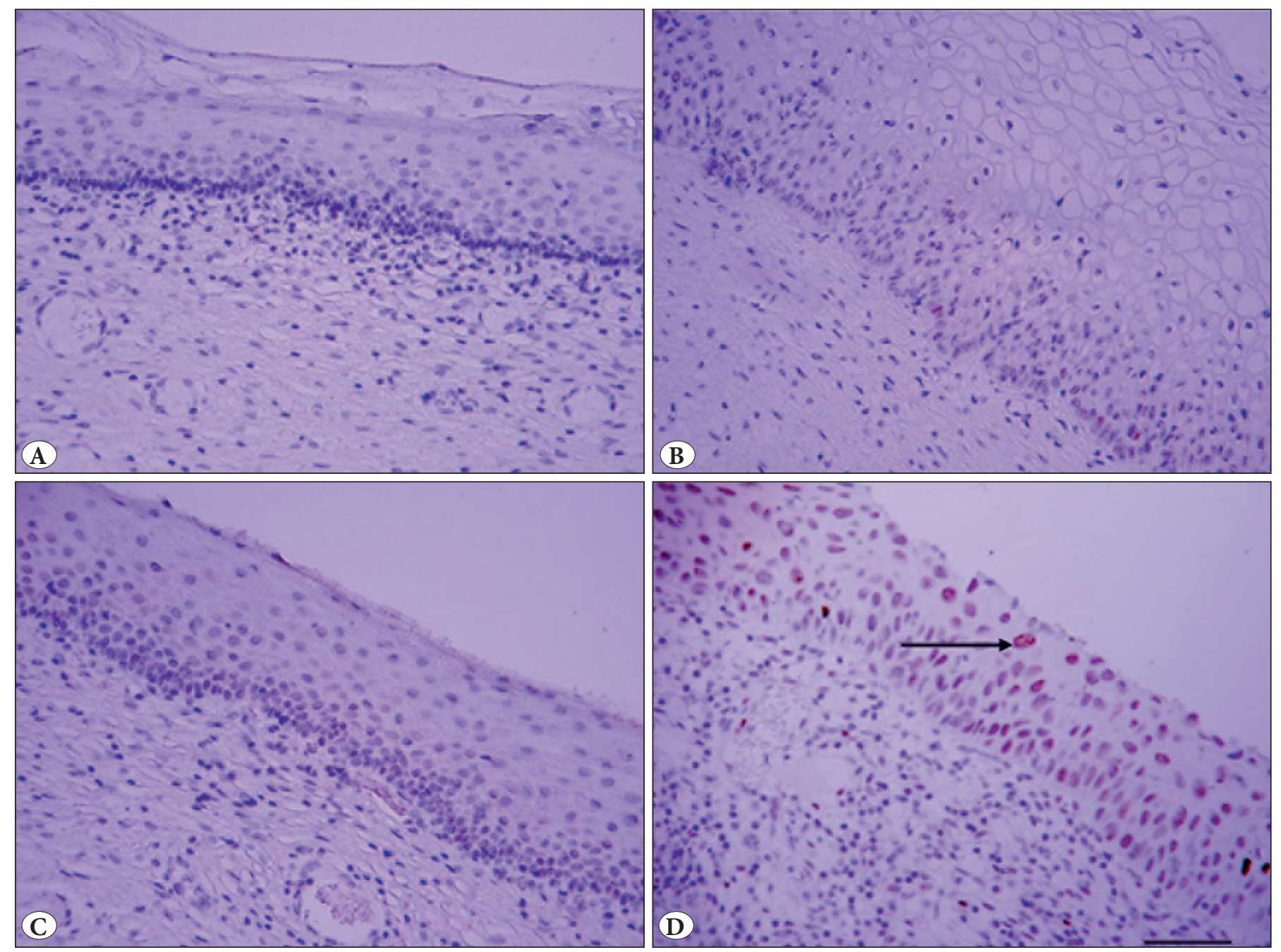

Figure 5: Representative photomicrograph of p53 expression in A) control group, B) CIN I, C) CIN II and D) CIN III . (p53; x200, scale bar-100 $\mu \mathrm{m}$, arrow indicated positively stained cells).

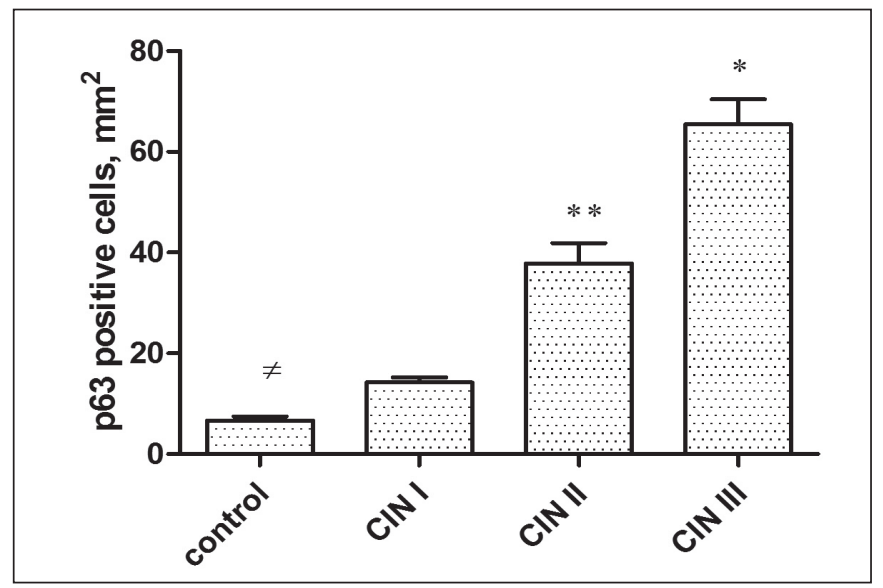

Figure 6: p63 expression in patients with CIN and control group. ${ }^{*} \mathrm{p}<0.0001$, CIN III vs. CIN I and CIN III vs. CIN II; ${ }^{* *} \mathrm{p}=0.0002$ compared CIN III vs. CIN II; $\neq \mathrm{p}<0.0001$ compared control group vs. CIN III vs. CIN II and vs. CIN I; Kruskal-Wallis test followed by Dunns' post test.
Ki- 67 could distinguish normal and benign conditions of cervix from precursor lesions of carcinoma, and has a strong prognostic value for progression to early CIN lesions $(6,7,9,27,28)$. Our study showed that patients with CIN III had increased $\mathrm{Ki}-67$ expression in multilayer squamous epithelium compared to CIN II and CIN I patients.

To conclude, the expression of Ki-67, p63 and p53 differed between CIN I, CIN II and CIN III. p63 and p53 were reliable biomarkers to distinguish reactive changes and CIN I, while all three biomarkers (Ki-67, p53 and p63) have a high degree of sensitivity and specificity to distinguish low and high grade neoplasia.

\section{CONFLICT of INTEREST}

The authors state no conflict of interest. 

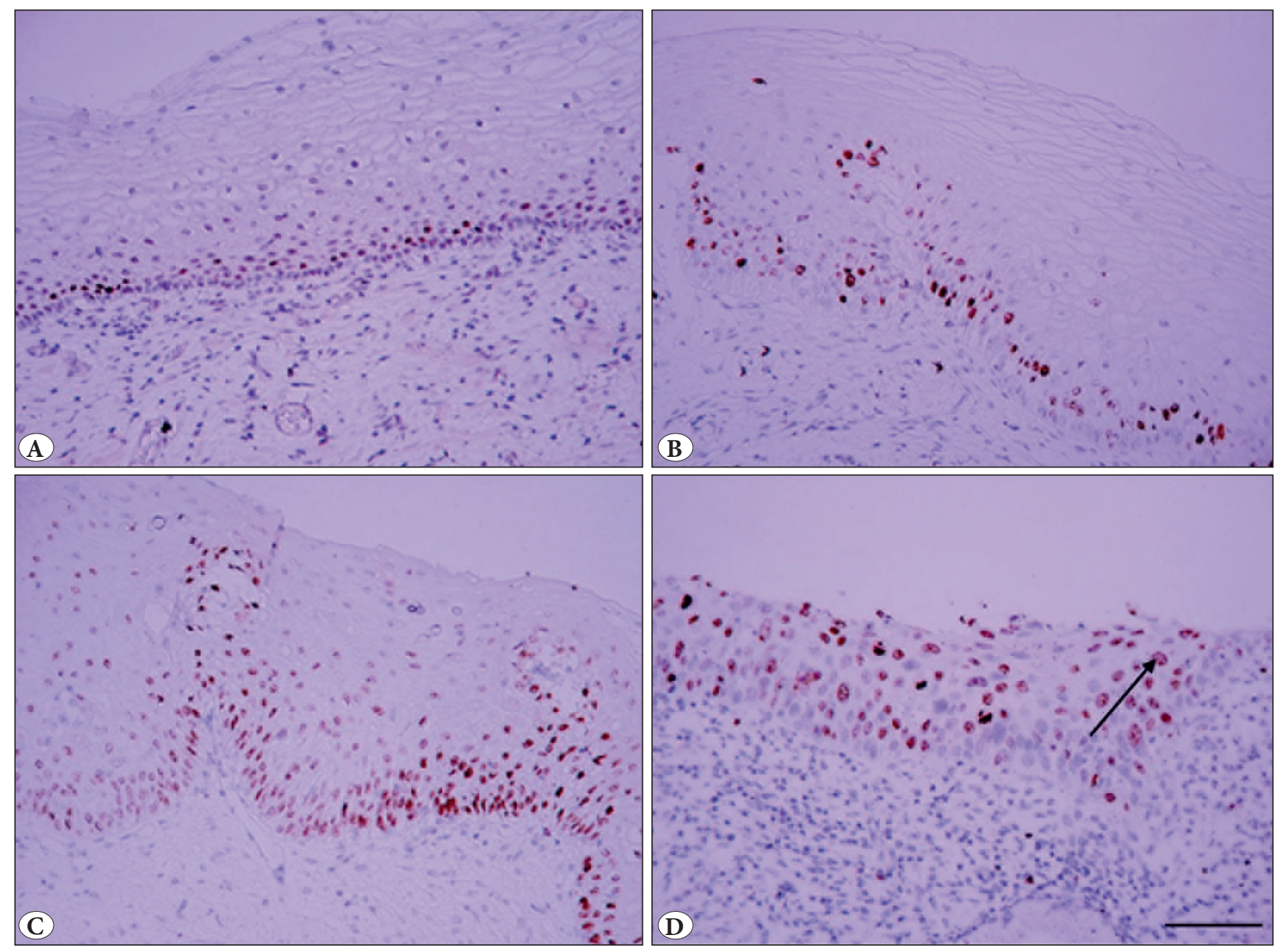

Figure 7: Representative photomicrograph of p63 expression in A) Control group, B) CIN I, C) CIN II and D) CIN III (p63; x200, scale bar-100 $\mu \mathrm{m}$, arrow indicated positively stained cells).

\section{FOUNDING SOURCE}

This study was supported by the project European Fund for Regional Development, Development of risk stratification method for cancer and premalignant lesions by using biomarkers", No 2014/0035/2DP/2.1.1.1.0/14/APIA/ VIAA/102 and by the PhD grant of Riga Stradins University No 2014-2016.

\section{REFERENCES}

1. Baak J, Kruse AJ, Janssen E, Diermen B. Predictive testing of early CIN behaviour by molecular biomarkers. Cell Oncol. 2005;27:277-80.

2. Kurman RJ, Carcangiu ML, Herrington CS, Young RH. WHO Classification of Tumours. 4th ed. Lyon: WHO; 2014.

3. Martin CM, O’Leary JJ, Phil D. Histology of cervical intraepithelial neoplasia and the role of biomarkers. Best Pract Res Clin Obstet Gynaecol. 2011;25:605-15.
4. Gurrola-Díaz CM, Suárez-Rincón AE, Vázquez-Camacho G, Buonocunto-Vázquez G, Rosales-Quintana S, Wentzensen N, von Knebel Doeberitz M. P16INK4a immunohistochemistry improves the reproducibility of the histological diagnosis of cervical intraepithelial neoplasia in cone biopsies. Gynecol Oncol. 2008; 111:120-4.

5. Schorge JO, Lea JS, Elias KJ, Rajanbabu R, Coleman RL, Miller DS, Ashfaq R. P16 as a molecular biomarker of cervical adenocarcinoma. Am J Obstet Gynecol. 2004;190:668-73.

6. Van Niekerk D, Guillaud M, Matisic J, Benedet JL, Freeberg JA, Follen M, MacAulay C. p16 and MIB1improve the sensitivity and specificity of the diagnosis of high grade squamous intraepithelial lesions: methodological issues in a report of 447 biopsies with consensus diagnosis and HPV HCII testing. Gynecol Oncol. 2007;107:S233-40.

7. Ozaki S, Zen Y, Inoue M. Biomarker expression in cervical intraepithelial neoplasia: Potential progression predictive factors for low-grade lesions. Hum Pathol. 2011;42:1007-12. 
8. Lobato S, Tafuri A, Fernandes PÁ, Caliari MV, Silva MX, Xavier MA, Vago AR. Minichromosome maintenance 7 protein is a reliable biological marker for human cervical progressive disease. J Gynecol Oncol. 2012;23:11-5.

9. Hanprasertpong J, Tungsinmunkong K, Chichareon S, Wootipoom V, Geater A, Buhachat R, Boonyapipat S. Correlation of p53 and Ki-67 (MIB-1) expressions with clinicopathological features and prognosis of early stage cervical squamous cell carcinomas. J Obstet Gynaecol Res. 2010;36:572-80.

10. Martinez-Rivera M, Siddik ZH. Resistance and gain-of-resistance phenotypes in cancers harboring wild-type p53. Biochem Pharmacol. 2012;83:1049-62.

11. Rezza G, Giuliani M, Garbuglia AR, Serraino D, Cappiello G, Migliore G, Branca M, Benedetto A, Ippolito G. Lack of association between p53 codon-72 polymorphism and squamous intraepithelial lesions in women with, or at risk for, human immunodeficiency virus and/or human papillomavirus infections. Cancer Epidemiol Biomarkers Prev. 2001;10:565-6.

12. Quade BJ, Yang A, Wang Y, Sun D, Park J, Sheets EE, Cviko A, Federschneider JM, Peters R, McKeon FD, Crum CP. Expression of the p53 homologue p63 in early cervical neoplasia. Gynecol Oncol. 2001;80:24-9.

13. Wentzensen N, von Knebel DM. Biomarkers in cervical cancer screening. Dis Markers. 2007;23:315-30.

14. Sankaranarayanan R, Budukh AM, Rajkumar R. Effective screening programmes for cervical cancer in low- and middle-income developing countries. Bull World Helath Org. 2001;79:954-62.

15. Dockter J, Schroder A, Hill C, Guzenski L, Monsonego J, Giachetti C. Clinical performance of the APTIMA HPV Assay for the detection of high-risk HPV and high-grade cervical lesions. J Clin Virol. 2009;45:S55-61.

16. Cuzick J, Clavel C, Petry KU, Meijer CJ, Hoyer H, Ratnam S, Szarewski A, Birembaut P, Kulasingam S, Sasieni P, Iftner T. Overview of the European and North American studies on HPV testing in primary cervical cancer screening. Int J Cancer. 2006;119:1095-101.

17. Franco EL Duarte-Franco E, Ferenczy A. Cervical cancer: epidemiology, prevention and the role of human papillomavirus infection. CMAJ. 2001;164:1017-25.

18. Jordan J, Martin-Hirsch P, Arbyn M, Schenck U, Baldauf JJ, Da Silva D, Anttila A, Nieminen P, Prendiville W. European guidelines for clinical management of abnormal cervical cytology, part 2. Cytopathology. 2009;20:5-16.
19. Vasilescu F, Ceauşu M, Tănase C, Stănculescu R, Vlădescu T, Ceauşu Z. P53, p63 and Ki-67 assessment in HPV-induced cervical neoplasia. Rom J Morphol Embryol. 2009;50:357-61.

20. Wang JL, Zheng BY, Li XD, Angström T, Lindström MS, Wallin KL. Predictive significance of the alterations of p16INK4A, p14ARF, p53, and proliferating cell nuclear antigenexpression in the progression of cervical cancer. Clin Cancer Res. 2004;10:240714.

21. Tosun G, Sendag F, Zeybek B, Cosan Terek M, Guven C, Zekiogly $\mathrm{O}$, Bilgin O. Immunohistochemical expressions of p16 and p53 proteins in cervical intraepithelial neoplasia and in benign cervical tissue. Eur J Gynaecol Oncol. 2010;31:627-31.

22. Zhang J, Wang L, Qiu M, Liu Z, Qian W, Yang Y, Wu S, Feng Y. The protein levels of MCM7 and p63 in evaluating lesion severity of cervical disease. Int J Gynecol Cancer. 2013;23:318-24.

23. Portari EA, Russomano FB, de Camargo MJ, Machado Gayer CR, da Rocha Guillobel HC, Santos-Rebouças CB, Brito Macedo JM. Immunohistochemical expression of cyclin D1, p16Ink4a, p21WAF1, and Ki-67 correlates with the severity of cervical neoplasia. Int J Gynecol Pathol. 2013;32:501-518.

24. Bao H, Wu Y. p16INK4A and Ki-67 immunostaining on cell blocks from residual ThinPrep material is helpful in identifying significant preneoplastic cervical lesions. Pathol Res Pract. 2011;207:216-9.

25. Khan AM, Singer A. Biomarkers in cervical precancer management: The new frontiers. Future Oncol. 2008;4:515-24.

26. Holem R, Skomedal H, Helland A. Immunohistochemical analysis of p53 protein overexpression in normal, premalignant and malignant tissues of the cervix uterine. J Pathol. 1993;169:216.

27. Quade BJ, Yang A, Wang Y, Sun D, Park J, Sheets EE, Cviko A, Federschneider JM, Peters R, McKeon FD, Crum CP. Expression of the p53 homologue p63 in early cervical neoplasia. Gynecol Oncol. 2001;80:24-9.

28. Türkçüoğlu I, Tezcan S, Kaygusuz G, Atabekoğlu CS, Ortaç F, Güngör M, Kankaya D, Sertçelik A. The role of p53, Bcl-2 and Ki-67 in premalignant cervical lesions and cervical cancer. Eur J Gynaecol Oncol. 2007;28:290-3. 